\title{
STRAFRECHTLICHE UBUNGEN
}

\author{
Siebzig Rechtsfälle und \\ siebzig lehrmäßige Aufgaben
}

von

Professor Dr. h. c. Emil Niethammer

Reichsgerichtsrat a. D.

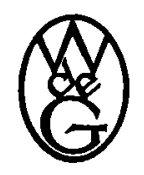

BERLIN 1948

WALTER DE GRUYTER \& CO.

vorm. G. J. Göschen'sche Verlagshandlung / J. Guttentag, Verlagsbuchhandlung Georg Reimer / Karl J. Tübner / Veit \& Comp. 
Archir-Nr 232546

Printed in Germany / Drud: Buchdruckerei ,Buckkunst", Berlin W 3 